REVISTA DE DERECHO UNED, NÚM. 14, 2014

\title{
DERECHO DE FRONTERA Y SEÑORÍOS ECLESIÁSTICOS EN LA EDAD MEDIA
}

\author{
BORDER LAW AND ECCLESIASTICAL DOMAINS IN THE \\ MIDDLE AGES \\ Dr. GonZalo Oliva Manso \\ Profesor-tutor de la UNED
}

Resumen: El estudio del derecho de frontera ha sido minusvalorado durante los últimos años y aún quedan grandes lagunas en su conocimiento que nos impiden conocer las estrechas relaciones que unen a los textos que lo forman. En este artículo se ha intentado subsanar esta carencia y se ha abordado el estudio de un fuero de reducida extensión como Valfermoso de las Monjas. El análisis se ha hecho a tres niveles: estructura, redacción y vocabulario, hallándose significativos paralelismos entre este texto y otro tan importante como Uclés. La conclusión a la que se llega es que la fundación de esta villa vino acompañada de la formulación de un derecho propio basado en una tradición preexistente en la región. Esta tradición no era oral sino que estaba plasmada por escrito en un texto que tuvo amplia difusión en los señoríos eclesiásticos.

Palabras clave: Derecho de frontera, derecho local, fuero, Valfermoso de las Monjas, Uclés.

Abstract: The study of the border law has been abandoned for years and there are still large gaps in their knowledge that prevent us from knowing the close ties between the texts. This article has tried to remedy this deficiency with the study of a charter of small size as Valfermoso de las Monjas. The analysis has been made at three levels: structure, writing and vocabulary, finding significant parallels between this text and another as important as Uclés. The conclusion that can be reached is that the foundation of this town was accompa- 
nied by the establishment of a law based on a pre-existing tradition in the region. This tradition was not oral but rather was written in a text that had wide circulation in the ecclesiastical domains.

Keywords: Border law, local law, charter, Valfermoso de las Monjas, Uclés.

Recepción original: 29/01/2014

Aceptación original: 27/02/2014

Sumario: I. Introducción. II. El fuero de Valfermoso de las Monjas. Naturaleza y Estructura. III. Valfermoso de las Monjas y Uclés. Concordancias; III.1. Estructura; III.2. Redacción; III.3. Vocabulario. IV. Conclusiones.

\section{INTRODUCCIÓN}

Corrían los primeros años de la década de 1180 cuando Juan Pascual de Atienza y Flamina, matrimonio de origen mozárabe, acordaron con el concejo de Atienza la compra de las apartadas tierras del río Badiel para su repoblación ${ }^{1}$. La transacción no despertó en éste ninguna suspicacia pues la pareja contaba con importante intereses patrimoniales en la pequeña localidad de Ledanca integrada en el alfoz atienzano. Sin embargo, el objetivo real de Juan Pascual era la segregación de estas tierras de la jurisdicción de Atienza, lo que consiguió en diciembre de 1185 como consta en el diploma expedido en Almazán por Alfonso VIII por el que le concedió los tributos reales pagados por los habitantes de estas tierras ${ }^{2}$. Apenas un año después y en un acto de liberalidad propio de la época decidieron fundar en sus nuevas posesiones un monasterio femenino y ponerlo bajo la advocación de San Juan Bautista.

Dos monjas francesas de la orden de Fontisgartari ${ }^{3}$, Nobila de Perigord y Guirarda salieron de la Gascuña para constituir el germen

${ }^{1}$ Los pormenores de estos primeros momentos de la vida de la localidad pueden seguirse en Molina Piñedo, R., Las señoras de Valfermoso, Guadalajara, AACHE Ediciones, Guadalajara, 1996, págs. 33-62. Molina da cuenta de un escrito inédito localizado en el mismo monasterio y que puede datarse en el siglo XIX llamado Noticias verdaderas y bien fundadas de el real Monasterio de S. Juan Bautista de Religiosas Benitas, Señoras de la villa de Balfermoso.

${ }^{2}$ González, J., El Reino de Castilla en la época de Alfonso VIII, Madrid, C. S. I. C. Escuela de Estudios Medievales, 1960, v. 2, doc. 445, págs. 764-766.

${ }^{3}$ En el silgo XVII se relacionó esta procedencia foránea con un posible filiación francesa de los donantes (ArgáIz, G. de, La soledad de San Benito y sus hijos en las iglesias de España y teatro monástico de la provincia Cartaginense, Madrid, Bernardo 
alrededor del cual se formó la comunidad monástica. No fueron fáciles estos primeros momentos pues Atienza no aceptó de buen grado esta amputación territorial y así consta que en 1194 Alfonso VIII tuvo que confirmar por dos veces la nueva situación ${ }^{4}$. Para finales de siglo las aguas se habían calmado, las monjas comenzaron a recibir sustanciosas donaciones ${ }^{5}$, el concejo de Atienza cedió finalmente ante el constante apoyo real al monasterio ${ }^{6}$ y, finalmente, éste se inauguró por fin el 27 de diciembre de 1200.

En estos primeros años uno de los momentos clave fue la concesión en 1189 de un fuero a la localidad. Su contenido, compuesto en su mayor parte de derecho penal y procesal más algunas ordenanzas para regular la actividad económica nos indica que la primera fase de atracción de pobladores había terminado y comenzaba una segunda en la que primaba la fijación de las reglas que habían de determinar la convivencia y la economía del lugar.

El proceso debió seguir las mismas pautas ya ensayadas en 1155 cuando el concejo de Atienza cedió la iglesia de San Salvador en beneficio de la villa de Sigüenza «con todos sus heredamientos, sus fueros y costumbres, según los hombres de dicha villa lo consignaron en su escrito y os lo entregaron ${ }^{7}$. De la misma forma en 1189 los vecinos habrían plasmado por escrito su derecho con la anuencia de los nuevos señores.

A pesar de su indudable interés legal el fuero de Valfermoso de las Monjas no ha gozado de la atención debida. García López apenas se limitó se señalar su carácter dual: fuero municipal como el de Guadalaja-

de Herbada, 1675, pág. 267). Otra teoría otorga un papel principal en la fundación del monasterio a la reina Leonor que buscaría en los dominios de su madre Leonor de Aquitania a estas religiosas (LAYNA SERrano, F., Historia de la villa de Atienza, Guadalajara, AACHE Ediciones, 2004, pág. 104)

${ }^{4}$ El primer diploma está fechado el 29 de enero y fue transcrito por GonZÁLEZ (ob. cit., vol. 3, núm, 620, págs. 102-103). El segundo, datado el 12 de diciembre, está conservado en el archivo del monasterio, y ha sido estudiado por GARCíA LÓPEZ, J. C. (La Alcarria en los dos primeros siglos de su Reconquista, Guadalajara, Instituto Provincial de Cultura Marqués de Santillana, 1973, pág. 60, nota 105) y Molina PiÑEdo, ob. cit, págs. 57.

${ }^{5}$ En 1197 don Rodrigo, obispo de Sigüenza, les hizo entrega de varias heredades sin más obligación que un pequeño censo de dos maravedís (Ib.).

${ }^{6}$ En 1198 Alfonso VIII expidió en la misma Atienza un último diploma aprobando la construcción del monasterio que fue confirmado por algunas de las más altas autoridades del reino (cita en BIBLIOTECA DE LA ACADEMIA DE HISTORIA, Colección Sobreira, V, fols. 99v y 102).

${ }^{7}$ Vid. Alvarado Planas, J., «El fuero latino de Sepúlveda de 1076» en Alvarado Planas, J. (coord.), Los fueros de Sepúlveda, Madrid, Centro de Estudios Ramón Areces, Universidad Nacional de Educación a Distancia, 2005 pág. 61. 
ra pero también carta puebla como Aragosa ${ }^{8}$. Nuestro fuero puede considerarse sin lugar a dudas como unos de los grandes desconocidos del panorama legal en la Edad Media y como se verá en las páginas siguientes este olvido se ve agravado por la importancia que tiene como nexo de unión a la hora de ir relacionando y engarzando en un esquema lógico los múltiples textos que conforman el derecho de frontera.

Más dedicación le han prestado en cambio los lingüistas pues el documento presenta ciertas singularidades léxicas que le diferencian de otros textos, legales o no, de las cercanías. Menéndez Pidal ${ }^{9}$ reseñó una serie de términos que achacaba a la permanencia de rasgos mozárabes en el habla de la localidad. Tras un lapso de cerca de cincuenta años Lapesa retomó la cuestión ${ }^{10}$ matizando las cuestiones de su predecesor al afirmar que las peculiaridades idiomáticas habría que buscarlas más allá de los Pirineos. Los mozarabismos serían realmente provenzalismos que habría que achacar al escriba, Ebrardo, «Ebrardvs capellanus» como figura al pie del pergamino, el cual sería de origen francés y habría acompañado a las monjas hasta su nueva residencia por lo que habiendo transcurrido apenas tres años de estancia en Castilla su forma de expresarse estaba aún condicionada por su lugar de procedencia ${ }^{11}$.

\section{EL FUERO DE VALFERMOSO. NATURALEZA Y ESTRUCTURA}

La primera cuestión que merece la pena resaltar se refiere a la propia naturaleza del texto pues se trata de un original y por tanto el contenido jurídico transcrito en él se corresponde exactamente con el vigente en 1189. Esto es particularmente importante si tenemos en

${ }^{8}$ GARcía LóPEZ, J. C., ob. cit., pág. 68.

${ }_{9}^{9}$ Menéndez Pidal, R., Orígenes del español: estado lingüístico de la península ibérica hasta el siglo XI, Madrid, Espasa-Calpe, 1980, págs. 92, 97, 285 y 439; y Crestomatía del español medieval, vol. 1, Madrid, Gredos, 1982, págs. 65-67.

${ }^{10}$ LAPESA, R., «Los provenzalismo del Fuero de Valfermoso de las Monjas (1189)», «Hispanic Studies in honor of E. de Chasca», Philological Quarterly, 51, 1, 1972, págs. 54-59 y «El Fuero de Valfermoso de las Monjas (1189)» en Homenaje a Álvaro Galmés de Fuentes, vol. 1, Oviedo, Madrid, Universidad de Oviedo, Gredos, págs. 43-98.

${ }^{11}$ «El clérigo que redacta las normas que han de regular la convivencia de los vecinos trata de escribir en latín, pero no lo hace en latín puro -probablemente no sabría hacerlo- sino con los ingredientes romances necesarios para que las gentes de la villa entendieran los preceptos; en realidad se limita de ordinario a dar apariencia latina a lo que ha pensado y acaso formulado en romance, latinizando la grafía, la fonética a que ésta corresponde, y la morfología... Ebrardo conoce bien el habla de las gentes del país, pero no ha olvidado su propia lengua, cuya fonética y morfología le hacen deformar palabras españolas, y cuyo léxico le suministra vocablos que sustituyen a los españoles que ignora u olvida» (Ib., 1985, pág. 94). 
cuenta que entre los fueros locales que podemos encuadrar dentro del grupo de fueros de frontera no hay otro que comparta esta característica. Situación la de Valfermoso que contrasta con la que encontramos en los importantes fueros de Uclés, Madrid, Brihuega, Alcalá de Henares, Molina o Sepúlveda que carecen de cualquier tipo de datación y sólo se pueden aventurar intervalos más o menos amplios en los que encuadrar el derecho allí contenido. Además, salvo Madrid y Sepúlveda, tampoco disponemos de la fecha de su puesta por escrito con lo que aún estamos más limitados en su estudio.

El segundo aspecto definidor del texto de Valfermoso y que va a ser estudiado con amplitud es el que se refiere a los estrechísimos vínculos que mantiene con el fuero romanceado de Uclés ${ }^{12}$ con artículos prácticamente idénticos y muchos de ellos siguiendo un mismo orden correlativo. Junto a este fuero semiextenso se pueden utilizar otros dos representantes del derecho ocilense: el fuero latino de $1179^{13}$ y, sobre todo, los estatutos de la cofradía de Santiago ${ }^{14}$.

Tanto García López como Lapesa transcribieron el texto de una tirada sin establecer división alguna de su contenido en artículos por lo que hemos tenido que subsanar este punto para poder ofrecer de una manera más directa las comparaciones con los otros fueros y poder señalar algunas peculiaridades de su estructura interna.

Comienza el texto con tres preceptos que habría que remontar a los primeros momentos de la vida de Valfermoso pues atañen a la regulación de las relaciones entre las monjas y los vecinos, señalando las obligaciones, pero también los privilegios de que gozarían éstos. Se establecen así unos primeros impuestos consistentes en el pago de unas determinadas cantidades en especie y en dinero (\# 1) y la prestación de unos servicios personales en las tierras que el monasterio gestionaba directamente (\# 2). Son apenas tres días a lo largo del año en el que los vecinos irán a arar, barbechar y segar corriendo la manutención por cuenta de las monjas. Se complementan estas dos normas con una inmediata (\# 3) por la que se reconoce el derecho de los vecinos a disponer libremente de las heredades recibidas pero siempre que el acto se realice con otra persona de la localidad. Beneficio

12 Rivera Garretas, M., La encomienda, el Priorato y la villa de Uclés en la Edad Media (1174-1310). Formación de un señorio de la Orden de Santiago, Madrid-Barcelona, Consejo Superior de Investigaciones Científicas, 1985, doc. 236, págs. 443-460

${ }^{13} \mathrm{Ib} .$, doc. 3, págs. 234-240.

${ }^{14} \mathrm{Ib}$., doc. 235, págs. 441-443. Un pequeño estudio de este documento fue realizado por Georg Gross, "La carta de la cofradía de Santiago: documento histórico lingüístico de mediados del siglo XII (según original)», Boletín de la Real Academia de la Historia, 194-1, 1997, págs. 71-82. 
mutuo, pues se garantiza un derecho de prelación a los vecinos, mientras que el monasterio se garantiza la percepción de las gabelas señaladas en el fuero al evitar la entrada de personas que pudieran invocar un fuero personal privilegiado con las correspondientes exenciones tributarias. Otros aspectos impositivos se pueden encontrar dispersos por el texto: imposición complementaria de Navidad (\# 29), exención de la mañería (\# 31) y reparto de caloñas con los vecinos (\# 90).

En el resto del fuero se pueden distinguir hasta cinco partes, no estrictamente homogéneas, pero si con bastantes rasgos comunes tanto en lo que se refiere a su posible origen como al contenido de las mismas. Una primera abarca los preceptos 4-28, dedicados mayoritariamente a asuntos de derecho penal con algunas pinceladas de procesal. Constatamos la presencia de similitudes más que notables con Uclés que parecen proceder de un texto en su mayor parte que iniciara sus artículos con la expresión «Totus homo qui...» y que aquí habría quedado reducida a "Qui...»

Estas concordancias se plasman gráficamente en el siguiente cuadro ${ }^{15}$ :

\begin{tabular}{|c|c|c|c|}
\hline VALFERMOSO & \multicolumn{3}{|c|}{ UCLÉS } \\
\hline 4 & 31 & & 5 \\
\hline 5 & \multicolumn{3}{|c|}{1} \\
\hline 6 & \\
\hline 7 & & & \\
\hline 8 & 46 & \multicolumn{2}{|c|}{187} \\
\hline 9 & 47 & \multicolumn{2}{|c|}{187} \\
\hline \multicolumn{4}{|l|}{10} \\
\hline \multicolumn{4}{|l|}{11} \\
\hline \multicolumn{4}{|l|}{12} \\
\hline 13 & $12 /$ & & 79 \\
\hline 14 & \multicolumn{3}{|c|}{75} \\
\hline 15 & & & \\
\hline 16 & 5 & 74 & 109 \\
\hline
\end{tabular}

\begin{tabular}{|c|c|c|}
\hline VALFERMOSO & \multicolumn{2}{|c|}{ UCLÉS } \\
\hline 17 & 6 & 22 \\
\hline 18 & 8 & 157 \\
\hline 19 & \multicolumn{2}{|c|}{9} \\
\hline 20 & \multicolumn{2}{|c|}{19} \\
\hline 21 & 20 & \multicolumn{2}{|c|}{52} \\
\hline 22 & \multicolumn{2}{|c|}{23} \\
\hline 23 & 25 & 126 \\
\hline 24 & \multicolumn{2}{|c|}{28} \\
\hline 25 & \multicolumn{2}{|c|}{29} \\
\hline 26 & 34 & 65 \\
\hline 27 & 35 & 166 \\
\hline 28 & \multicolumn{2}{|c|}{39} \\
\hline & \multicolumn{2}{|c}{} \\
\hline
\end{tabular}

A continuación, siguen ocho artículos (\#\# 29-38), descontando los dos ya tratados con anterioridad, fundamentalmente de derecho procesal, pero que se acercan también a cuestiones de derecho civil y penal ${ }^{16}$.

${ }^{15}$ En las celdas sin color: «Qui...» u otra expresión similar. En las celdas en color: «Totus homo qui...»o «Homo / Mulier qui...» (Uclés 12, 19, 179).

16 Todas las concordancias pueden seguirse en el cuadro que figura como anexo. 
Un tercer bloque se prolonga hasta la norma 57 y volvemos a encontrar una presencia mayoritaria del derecho penal ocilense y en muy escasa medida procesal y mercantil.

El detalle más interesante es que hasta el precepto 49 existe un orden subyacente, que coincide con Uclés, que presente en el comienzo del fuero se había interrumpido con la introducción del bloque anterior ${ }^{17}$. Si leemos esta serie secundaria constataremos que sus artículos finales (\#\# 44, 45, 46, 47, 48, 49) se centran en la protección de heredades y animales. Temática que se repite hasta el final (\#\# 50, 51, $53,54,55,56,57$ ) con una única excepción (\# 52). Lapsus en cierta medida justificado pues el copista vio que se estaban tratando diversos puntos referentes a la ganadería (\#\# 51, 53, 54, 55) y se dejó llevar depositando a trasmano un artículo mitad mercantil mitad penal donde se regulan los precios de la carne y el castigo por su manipulación.

El lugar más adecuado para su ubicación habría sido al final de esta serie iniciando este nuevo grupo (\#\# 58, 59, 60, 61, 62 y 63) que forma una auténtica ordenanza sobre el mercado al tratar cuestiones sobre precios, pesos y medidas.

Finaliza el fuero con treinta y un artículos (\#\# 64-94) que no constituyen una serie ni mucho menos homogénea como las anteriores y con una temática absolutamente variada.

Un dato curioso que nos vuelve a indicar la forma de actuar del copista la tenemos en el artículo que inicia este grupo absolutamente fuera de contexto pues debería de estar situado junto a la serie que regula la protección de heredades y en cambio se ha situado en esta posición porque incluye el término «almut». El copista ha considerado de forma instintiva que está tratando alguna cuestión relacionada con medidas y ahí lo ha dejado sin pararse a leer y entender que el fondo del precepto es el castigo al pastor que ha permitido que su rebaño se introduzca en campos labrados, por cada doce ovejas o cabras se ha de pagar de multa un almud del cereal correspondiente ${ }^{18}$.

${ }^{17}$ Vid. infra.

18 Realmente el verdadero y último sentido de esta escueta norma en equiparar a efectos penales a un determinado grupo de animales de ganado menor (ovino o caprino) con una unidad de ganado mayor (vacuno o equino). Medinaceli [c. 1180]: «Cuyo ganado mayor danno ficiere de dia en miese, por cada cabeza peche un al, et dél danno apreciado: e ganado menudo a X cabezas un al o el danno apreciado, qual mas quisiere el duenno de la miese», pero también Santa María de Cortes (1182) 31; Guadalajara 36; Brihuega 108,187, 269, 270; Molina 28. 


\section{VALFERMOSO DE LAS MONJAS Y UCLÉS. CONCORDANCIAS}

El contrapunto del fuero de Valfermoso lo pone el texto romanceado de Uclés. Se trata de una recopilación de 216 artículos $^{19}$ y como indica en su comienzo se trata de un fuero consensuado entre las autoridades, la Orden de Santiago, y los habitantes de la villa: «Hec est carta que fecerunt concilio et seniores de Ucles pro salute de maximo usque ad minimum». La fecha del mismo habría que situarla con anterioridad a $1242^{20}$, en que la orden de Santiago mejora las condiciones de los vecinos ocilenses. Estas novedades deberían haber sido incluidas en la carta del fuero como así se lo indica el diploma de amejoramiento y sin embargo no figuran por ningún lado ${ }^{21}$.

Uclés había sido recuperada de manos musulmanas en 1157 siendo entregada al a la Orden de San Juan quien la administró durante apenas once años antes de volver a la tutela real. En 1174 pasó definitivamente a pertenecer a la Orden de Santiago, que estableció aquí su casa principal. Este nuevo contexto trajo consigo la concesión del fuero latino de 1179 como instrumento legal que regulara el nexo villa-orden. Este texto está formado por 29 artículos donde se fija el reparto de las esferas de poder entre los vecinos y la orden de Santiago, y las relaciones básicas de convivencia dentro de la villa y con las localidades cercanas y que vendrían a sustituir al que con anterioridad habían tenido los ocilenses con el rey o con los sanjuanistas. Tiene este fuero un carácter de derecho exclusivo y privilegiado que lo diferencia de otras zonas del reino menos expuestos al peligro musulmán y cuya seguridad se grava con mayores prestaciones.

Con posterioridad la resolución de los conflictos que se fueron sucediendo en la vida cotidiana de la villa irían aumentado el fuero romanceado y situándose físicamente en el libro a continuación de las anteriores hasta llegar a la redacción actualmente conocida. Rivera ha postulado la existencia de varias redacciones previas que acabarían por dar lugar a este fuero. La justificación a esta apreciación es-

${ }^{19}$ Originalmente debieron ser algunos más pues nos faltan los últimos folios lo que unido a la variabilidad en el número de hojas que componen los cuadernos que conservamos impiden hacerse una idea exacta del número de artículos que han quedado relegados al olvido (RIVERA GARRETAS, M., "El fuero de Uclés (siglos XII-XIV)», Anuario de Historia del Derecho Español, 52, 1982, págs. 249-250).

${ }^{20}$ Rivera GarRetas, M., «El fuero...», ob. cit., págs. 252-253.

21 «E demás d'esto e por mas firmedumbre e por que esto fecho sea por fuero por siempre, esta nota d'estas cartas seelladas e que son partidas par ABC fiziémosla poner en las cartas del fuero d'Uclés, en la carta que tiene el concejo e en la carta que tiene la Orden en el castiello d'Uclés» (RIVERA Garretas, M., La encomienda ..., ob. cit., doc. 188, págs. 394-395). 
taría en la existencia de fórmulas de inicio muy comunes a lo largo del fuero, cada una las cuales vendría a individualizar una de estas redacciones ${ }^{22}$. Manifestaba también la imposibilidad, con las fuentes disponibles, de relacionar estas series con los privilegios originales de los que hubieran sido extractados ${ }^{23}$.

\section{II.1. Estructura}

Por nuestra parte sí creemos que es posible rastrear entre los otros fueros de frontera varias series de preceptos concordantes con un mismo orden correlativo, encubierto por la intromisión de otros posteriores que han ido entreverando el texto ${ }^{24}$.

Los primeros ejemplos los encontramos al poco de comenzar el texto cuando se regulan las agresiones con o sin armas continuadas al poco con otras dos que tratan la penalización de los insultos. Dos preceptos consecutivos no constituyen indicios que nos muevan a pensar en una relación estrecha entre ambos fueros, aunque la coincidencia de temática apuntala en cierta medida estas relaciones ${ }^{25}$.

\begin{tabular}{|l|c|c|c|c|}
\hline Valfermoso & 5 & 6 & 8 & 9 \\
\hline Uclés & 1 & 2 & 46 & 47 \\
\hline
\end{tabular}

Más relevantes son las dos siguientes series. La primera de ellas se refiere a ciertos aspectos del ordenamiento de la actividad comercial dentro de la villa y que en Uclés se encuentran en cuatro preceptos (FRU 181-183) que aparecen casi correlativamente en FVM y que se completan con algunas soluciones también presentes en el fuero de Alcalá de Henares:

\begin{tabular}{|l|c|c|c|c|c|c|}
\hline Valfermoso & 58 & 59 & 60 & 61 & 62 & 63 \\
\hline Uclés & 181 & 182 & & & 183 & 180 \\
\hline Alcalá de Henares & & & 202 & 206 & & \\
\hline
\end{tabular}

${ }^{22}$ Ib., págs. 279-281.

${ }^{23}$ Ib., pág. 282.

${ }^{24}$ Unas primeras impresiones están recogidas en nuestro anterior trabajo «Orígenes del derecho sepulvedano», en SuÁrez Bilbao F, y Gambra A. (coord.), Los fueros de Sepúlveda y las sociedades de frontera. II Symposium internacional de estudios históricos de Sepúlveda, Madrid, Dyckinson, 2008, págs. 51-102, especialmente en las págs. 87-90.

${ }^{25}$ En adelante utilizaremos los siguientes acrónimos para referirnos a los fueros más utilizados: Valfermoso de las Monjas (FVM), Uclés romance (FRU), cofradía de Santiago de Uclés (CSU), Brihuega $(\mathrm{FBr})$. 
En FVM se ha optado por dejar de lado el desorden primigenio presente en FRU y separar los dos preceptos que versan sobre precios de aquellos centrados en la regulación de pesas y medidas. Esta división se continúa en los dos artículos centrales que completan la serie pues el primero indica los precios de los productos elaborados por los zapateros mientras el segundo señala que los panes se vendan al peso y no por unidades.

En esta otra serie se mantiene el orden correlativo de las normas que lo integran pero la temática es totalmente diferente en cada uno de ellas:

\begin{tabular}{|l|c|c|c|c|c|}
\hline Valfermoso & 70 & 71 & 72 & 73 & 74 \\
\hline Uclés & 78 & 82 & 117 & 121 & 124 \\
\hline
\end{tabular}

Todo lo anterior ya nos hace levantar sospechas un tanto fundadas sobre una procedencia común. La prueba definitiva de esa vinculación está en la última serie que ofrecemos y que abarca un número mucho mayor de capítulos equivalentes. Se trata del nada desdeñable número de veinticuatro preceptos, con una única ruptura del orden en FVM 40.

\begin{tabular}{|c|c|}
\hline VALFERMOSO & UCLÉS \\
\hline 16 & $5 / 74 / 109$ \\
\hline 17 & $6 / 22$ \\
\hline 18 & $8 / 157$ \\
\hline 19 & 9 \\
\hline 20 & 19 \\
\hline 21 & $20 / 52$ \\
\hline 22 & 23 \\
\hline 23 & $25 / 126$ \\
\hline 24 & 28 \\
\hline 25 & 29 \\
\hline 26 & $34 / 65$ \\
\hline 27 & $35 / 166$ \\
\hline
\end{tabular}

\begin{tabular}{|c|c|}
\hline VALFERMOSO & UCLÉS \\
\hline 28 & 39 \\
\hline 39 & 42 \\
\hline 40 & 65 \\
\hline 41 & 43 \\
\hline 42 & $45 / 113$ \\
\hline 43 & $49 / 200$ \\
\hline 44 & 51 \\
\hline 45 & 54 \\
\hline 46 & 55 \\
\hline 47 & $56 / 170$ \\
\hline 48 & 57 \\
\hline 49 & 58 \\
\hline
\end{tabular}

Como se observa FVM viene en ocasiones a corresponderse con varios artículos de FRU. En la mayoría de los casos la explicación viene dada por el tratamiento más elaborado que hace FRU del derecho de frontera de modo que una parte del precepto se reutiliza en otros que tratan sobre cuestiones similares, bien sea por la conducta cometida o por la pena a aplicar. Es el caso de FVM 16 donde se castiga a quienes sin autorización de los jueces han reptado a su oponen- 
te sin haber solicitado la previa autorización judicial. El combate que originariamente tendría una naturaleza jurídica ahora se ha transformado en un acto privado, una simple reyerta privada, que debe ser castigado con el pago de una multa de 60 sueldos. FRU 5 prácticamente tiene la misma redacción con el único cambio de la penalidad que ahora es de diez maravedís. Esta cuestión viene a tratarse dos veces más en el texto ocilense, primero en FRU 74 pero referido únicamente al delito de robo y en FRU 109 donde se mezcla con las prendas efectuadas igualmente sin autorización. En este caso la pena es también de sesenta, pero no sueldos sino mencales ${ }^{26}$.

En los restantes, en cambio, se puede apreciar con estas duplicidades el modo de trabajar de Ebrardo que utiliza la estructura de un texto anterior como armazón pero sustituyendo, en ocasiones, un artículo por otro parecido bien sea por su fondo legal o simplemente en razón de similitudes estilísticas y terminológicas.

Es el caso de FVM 17 donde se trata la problemática de la negativa a la toma de prendas. Este trámite puede efectuarse en un primer momento por el interesado acompañado de vecino que actúe como testigo pero si el demandado se niega e impide el paso a su vivienda ha de acatarse esta negativa y no proceder violentamente bajo multa de cinco sueldos. FRU 6 por su parte recoge el trámite subsiguiente, pues es ahora el sayón quien debe efectuar la prenda encontrándose asimismo con la resistencia del demandado a permitirle la entrada al domicilio. El resultado de esta desobediencia a la autoridad local, personificada en este oficial, es la imposición de una multa. La redacción es prácticamente igual, salvando el hecho de que FVM es más prolijo en detalles. FRU 22 reitera la obligatoriedad de la presencia de al menos un vecino cuando la toma de prendas se efectúa por un particular.

Análogamente ocurre en FVM 18 donde se regulan el tema de la presentación de un fiador por parte del demandado lo que implica la inmediata devolución de las prendas que como garantía había tomado su oponente. Si éste por la razón que fuese se negara a aceptar el fiador vendría a entregarlas con el doble del valor de lo tomado. En el supuesto de que el demandado no pudiera cumplir este requisito los bienes tomados permanecerían en depósito hasta la finalización del pleito: «ibi iaguan suos pignos usque directum faciat». De manera semejante aparece regulado este tema en FRU 157, pero la negativa a recibir al sobrelevador, término utilizado en esta villa, implica auto-

${ }^{26}$ Conclusiones parecidas puede obtenerse del análisis de otros preceptos de FVM (\#\# 21, 26, 27, 42, 47). 
máticamente la obligación por parte del demandante de abonar una multa de sesenta mencales, no mencionándose la imposibilidad de presentación de fiador por parte del demandado. No obstante, este punto si se puede observar en Uclés pero al comienzo del texto. En FRU 8, con una redacción un tanto críptica, se viene a decir prácticamente lo mismo. El demandado que sostuviera que presentó fiador y hubiera testigos que lo negaran no podrá recuperar las prendas que permanecerán en depósito hasta que cumpla el requisito y la expresión es idéntica: «ibi iagan suos pignos usque directum faciat». Esta expresión no se puede hallar en FVM, FRU o cualquier otro de los fueros de frontera por lo que sólo puede atribuirse su presencia en estos fueros a un texto común a ambos.

El contenido del siguiente precepto, FVM 23, tiene que ver con los ganados tomados como garantía y su permanencia obligada en las dependencias del prendador de modo que si se constata su presencia fuera de ellas viene obligado a devolverlos con carácter inmediato. Su homólogo sería FRU 126 aunque en este caso no se menciona la restitución y sí una multa de cinco sueldos. En esta ocasión tampoco se rompe la secuencia pues si nos trasladamos a FRU vemos como figura el tema de las prendas y se tratan puntos muy similares a FVM 23 justamente donde deberíamos haber esperado su homólogo. En FRU 24 se regula la cuestión de la toma de ganado en concepto de prenda por un particular y su posterior custodia hasta que el demandado se atuviera a derecho pero es en el siguiente, FRU 25, donde está la clave. Esta norma de significado más oscuro contiene la expresión: «et por el pendra levaren aut suspecta le habuerint que cum suo pane levaron» que nos recuerda a la que aparece en FVM 23: «det directum quod de sua casa non exunt nec cum suo pane». Como en el caso anterior la expresión «cum suo pane» no aparece en ningún otro precepto de los fueros de la frontera.

En FVM 43 se trata una formalidad de las firmas otorgadas en juicio de modo que quien las presta «iuret super illos quod ueritatem otorgant» y lo hace de una forma general y aplicable a cuantas situaciones semejantes se puedan presentar en un procedimiento; por su parte, FRU 200 se centra en un supuesto concreto. Valfermoso afirma que cuando hay una pluralidad de testimonios que acreditan un mismo hecho las firmas son solidarias y cada uno responde no sólo de su propio testimonio sino de la veracidad de los hechos afirmada por los otros testigos. A continuación se establece la finalización de las actuaciones en su contra en caso de que no se cumpla este requisito. En Uclés ya no hablamos de simples testigos sino de los propios imputados por delitos graves, y que están sometidos a un procedimien- 
to especial como es el riepto en una acusación múltiple. Si uno de ellos se compromete a lidiar en nombre de todos sus compañeros debe de jurar "quod illos compañeros vertad firmaron» o en caso contrario deberá ser otro el que luche. Por su parte FRU 49 se centra en un momento posterior cuando el demandante que no se fía del testimonio otorgado lo recurre ante el tribunal. Ahora el lenguaje es opuesto al anterior y donde FVM decía: «quod ueritatem otorgant», FRU dice: «mentira iurest o mentira otorgest o falso testimonio dixisti».

\section{III.2 Redacción}

Comprobados los estrechos vínculos que comparten Valfermoso y Uclés, desde un punto de vista estructural hay que tratar ahora sus similitudes estilísticas que no desmerecen a los anteriores y que nos permiten afirmar sin duda alguna el parentesco íntimo entre ambos. La entidad de estos parecidos es muy amplia y podemos encontrar desde artículos prácticamente iguales, a otros con redacciones semejantes en grados muy variables.

En lo que respecta a normas literales en uno y otro texto podemos mostrar un par de ejemplos:

VALFERMOSO 16: «Totus homo qui litem petierit a suo companero sine mandamiento dalcaldes pectet LX solidos».

VaLFERmoso 39: «Totus homo qui iudicium habuerit cum suo vicino et plazo posuerit por uoca de los alcaldes et noctem lo fecerit in manu de illos fideles et uno de illos alcaldes, et dicant quomodo fecerunt nocte fulan et fulan et dica[n]t illo alcalde quales es en terra, et si non quisierit dicere, pecte[n]t illo pecho de illo iudicio et finiat. Et illos contesseros flegue[n]t illos alcaldes, et si non quesierint dicere pectent $\mathrm{V}$ solidos ad aquel qui los demandaret. Et ille qui posuerit plazo et no sera al p[1]azo cadat si firmaren quod non fuerit al plazo».
UCLÉS 5: «Totus homo qui littem petierit a suo vicino sine mandato de alcaldes pectet $\mathrm{X}$ morabetinos».

UCLÉs 42: «Totus homo qui iudicio habuerit cum suo vicino et plazo posuerit per voca de alcaldes et nocte lo fecerit in manu de illos fideles. Et uno de illos alcaldes dicat quomodo fecerunt nocte fulan et fulan, et dicat illo alcalde qual es in terra. Et si noluerit dicere, pectet illo pecto de illo iudicio et finiat. Et illos contessores flegens illos alcaldes, et qui noluerit afflegar pectet I morabetino ad alio et pignoret usque los afflegaret». 
No es el único caso ya que podríamos continuar la comparativa con estos otros:

\begin{tabular}{|l|c|c|c|c|c|c|c|c|c|c|c|c|c|c|c|c|}
\hline Valfermoso & 4 & 8 & 9 & 17 & 19 & 20 & 25 & 26 & 28 & 39 & 44 & 45 & 46 & 47 & 48 & 49 \\
\hline Uclés & 31 & 46 & 47 & 6 & 9 & 19 & 29 & 34 & 39 & 42 & 51 & 54 & 55 & 56 & 57 & 58 \\
\hline
\end{tabular}

Como se ve todos ellos están situados en la primera parte de Uclés lo que nos lleva a pensar en la existencia de un texto de derecho de frontera recogido en la parte inicial de ambos fueros donde se mezcló con otros materiales. La realidad de este texto perdido también se reafirma al comprobar como muchos de estos preceptos también estaban presentes en la extensa serie de orden correlativo.

Otro grupo de normas coinciden en su fondo jurídico además de presentar redacciones con muchos puntos en común aunque no exista una literalidad tan marcada como en las anteriores

La tendencia es que FVM sea más sencillo que FRU y que éste añada aspectos nuevos sobre el texto primitivo representado por su homólogo. Por ejemplo, en FVM 42 muy conciso se limita a señalar que el demandado por no pagar una deuda debe o entregar el dinero o presentar garantías por el duplo del valor requerido so pena de verse condenado inmediatamente. En cambio, FRU 113 mantienen lo anterior y añade un plazo de nueve días para responder a la demanda y aumenta las garantías al señalar que el acusado insolvente debe ser encadenado ( mittat suo pede») y debe jurar esta circunstancia.

VALFERMOSO 42: «Totus homo ad quem per auer fecerint iurare pongant lauer dauant aut pignus in duplo, et si esto non fecerint per hoc cadat».
UCLÉS 113: «Qui habuerit aver a dar et manifestum fuerit, intret in novem dias; et a cabo de novem dies adducat pignos in duplo vel auro in cabal. Et si non invenerit aver, mittat suo pede et iuret que no lo habet. Et si hoc non fecerit, dupplet suo aver sine iudicio».

No obstante hay veces en que Valfermoso presenta un artículo más trabajado y completo que Uclés. Así ocurre cuando se legisla sobre la violencia sexual contra las mujeres. 
VALFERMOSO 13: "Qui forsauerit mulierem pectet CCC solidos si firmare potuerit si fuerit in uilla cum tribus uicinis aut filiis uicinorum si de foris cum duobus qui uiderunt quod alleuum faciebat illi. Si istam firmam haberet non potuerit et firmas habuerit qui uiderunt illam uenire rascatam et dando uoces iuret ille de quo clamorem habuerit cum XII et si complere non potuerit de iuramento pectet CCC solidos et si non potuerit habere nec istam firmam nec aliam iuret cum duobus quod eam non forsauit nec alleuum illi fecit. Si isto complere non poterit sit inimicus».
UCLÉs 12: «Homo qui mulier aliena o filia aliena forçaret pectet $\mathrm{C}$ morabetinos et a palatio qual habet in villa, et exeat homizero et qui cum illo fuerit».

Uclés 179: «Mulier qui forcada fuerit, si firmas habuerit quia ille que dicit fecit ei força, pectet foro de villa. Et si non habuerit istas et alias habuerint qui viderunt eam plorantem aut facientem suam scissam et dicentem: Fulan fecit mihi ista forcia, iuret ille cum XII et si ista mulier non fecerit sicut scriptum est, non respondeat ei».

Partimos aquí de un precepto típico de derecho penal medieval (FRU 12). En apenas una línea se presenta una conducta ilícita y la pena correspondiente. La violación de una mujer se castiga con una fuerte cantidad, la misma que el homicidio, y con la declaración de enemistad para el culpable que lo expulsa de la comunidad y lo sitúa fuera de la ley. A partir de aquí cada fuero (FRU 179 y FVM 13) irán añadiendo otras cuestiones accesorias de derecho procesal hasta diseñar una sencilla, pero completa, versión del procedimiento a seguir en este tipo de delitos, fijándose el número mínimo de testigos necesarios para acreditar los hechos, el número de cojuradores preciso para salvarse en cada caso,... En ocasiones, como en FRU, lo encontramos disperso a lo largo del fuero, mientras que en otras, caso de FVM, ya ha sido condesado en una misma norma.

Otros ejemplos de redacciones similares se pueden seguir en este cuadro:

\begin{tabular}{|c|c|}
\hline VALFERMOSO & UCLÉS \\
\hline 5 & 1 \\
\hline 6 & $2 / 3$ \\
\hline 14 & 75 \\
\hline 18 & $8 / 157$ \\
\hline 21 & $20 / 52$ \\
\hline 22 & 23 \\
\hline 23 & $25 / 126$ \\
\hline 24 & 28 \\
\hline
\end{tabular}

\begin{tabular}{|c|c|}
\hline VALFERMOSO & UCLÉS \\
\hline 62 & 183 \\
\hline 63 & 180 \\
\hline 70 & 78 \\
\hline 71 & 82 \\
\hline 72 & 117 \\
\hline 73 & 121 \\
\hline 74 & 124 \\
\hline 75 & 71 \\
\hline
\end{tabular}

(C) UNED. Revista de Derecho UNED, núm. 14, 2014 


\begin{tabular}{|c|c|}
\hline VALFERMOSO & UCLÉS \\
\hline 27 & $35 / 166$ \\
\hline 40 & 65 \\
\hline 41 & 43 \\
\hline 51 & 50 \\
\hline 57 & 152 \\
\hline 58 & 181 \\
\hline 59 & 182 \\
\hline
\end{tabular}

\begin{tabular}{|c|c|}
\hline VALFERMOSO & UCLÉS \\
\hline 76 & $37 / 97$ \\
\hline 80 & 132 \\
\hline 81 & 146 \\
\hline 82 & $118 / 134$ \\
\hline 87 & 80 \\
\hline 90 & 32 \\
\hline & \\
\hline
\end{tabular}

Siguiendo un orden descendente, podemos encontrar un tercer nivel con el que aumentar el número de preceptos afines. En este caso se trata de pequeños matices que no forman el núcleo del precepto pero indican un fondo común del que viven ambos fueros.

\begin{tabular}{|l|c|c|c|c|c|c|}
\hline Valfermoso & 30 & 43 & 52 & 65 & 77 & 91 \\
\hline Uclés & 195 & 200 & 212 & 127 & 194 & 127 \\
\hline
\end{tabular}

En este caso y al contrario que el grupo de concordancias literales todos estos ejemplos proceden de la segunda mitad del texto de FRU ${ }^{27}$. Se trata de un derecho más moderno que utiliza soluciones ya habituales en la zona y que debería situarse a continuación del texto como en su caso deberían haber ido las cláusulas del amejoramiento de 1242.

El primero de estos artículos nos muestra las soluciones coincidentes que se dan tanto en FVM 30 como en FRU 195 para la pérdida del ganado ajeno por parte de los pastores a los que ha sido encomendado. Estas soluciones cambian únicamente en la duración de este acuerdo de custodia. Mientras Valfermoso ${ }^{28}$ recoge el supuesto de los animales que regresan cada día a la villa, Uclés se centra en aquellos otros que permanecen durante un período dilatado en los «extremos» del término municipal. En ambos casos la responsabilidad del pastor es completa y en caso de juramento del amo debe pagar su importe, pero mientras en Valfermoso no se admite ninguna pérdida, en Uclés se permite la pérdida de hasta cinco cabezas de ganado sin que sea preciso presentar las pieles del animal con las señales pertinentes que actuarían como justificantes. Además los pleitos deberán sustanciarse en la mesta u

${ }^{27}$ Páginas atrás hemos visto las relaciones entre FVM 43 y FRU 49. No lo hacemos en esta ocasión pues no presentan paralelismos estilísticos ni tratan una situación similar.

${ }^{28}$ Lo que no podría ser de otra manera si tenemos en cuenta que el término de Valfermoso de las Monjas debía ser bastante reducido pues procedía de la donación de un particular acomodado que ni siquiera pertenecía a la nobleza de sangre y que además tuvo que adquirirlo con anterioridad. 
organismo local que agruparía a los ganaderos y en caso de llevarlo a otra instancia el pastor se hace acreedor a una fuerte multa.

Otros de los ejemplos presentes en el cuadro es el referente a la negativa a la devolución de las prendas. FVM 65 señala la existencia de una orden expresa del aparato judicial de la localidad al completo. Juez y alcaldes actuando de consuno han ordenado esa restitución y el tomador de las prendas se niega a ello. La pena es especialmente dura: 10 maravedíes. Unos artículos más adelante en FVM 91 se regulan otros dos supuestos, uno semejante al anterior: la orden expresa por parte de los alcaldes y otro nuevo: la entrega previa por parte del demandado de las cantidades en litigio. Se considera ahora que la desobediencia no es tan grave y la pena se reduce al doble del valor de los bienes prendados. Por su parte, FRU 127 cambia el infractor, en este caso estamos ante un alcalde que no restituye las prendas pese a una orden en firme de sus compañeros. La multa es muy inferior a los supuestos anteriores, apenas un maravedí y medio a repartir entre las autoridades y el particular. Se presupone aquí que la desobediencia es una dejación de las funciones y por tanto se trata de un comportamiento menos punible que el enriquecimiento ilícito. Estos parecidos legales ya se tornan en un derecho coincidente cuando comparamos el texto de Valfermoso con las normas que rigen la cofradía de Santiago de Uclés.

VALFERmoso 91: «Totus homo qui pignos tenuerit de suo uicino et soltos fuerint ante alcaldes aut pagado fuerit de suo auer et non dederit illos pignos et in sua manu transnoctauerint, dupplet illos pignos...
Cofradía de Santiago de Uclés: «Tot confratre qui diere dereio et nol dieren sos penos et trasnoctaren duplenielos».

Terminamos esta serie con el tema de la creación de las dehesas, es decir la transformación de un terreno particular usado para la alimentación de los animales en un espacio dotado de una especial protección. En FVM 77 la autorización puede ser solicitada por cualquier vecino pero se requiere el cumplimiento de dos condiciones: el espacio a proteger deberá tener un tamaño inferior a dos aranzadas y estará debidamente señalado con césped. FRU 210 permite tanto la protección temporal, de marzo hasta San Miguel, y señalado como en el caso anterior con césped y la permanente, siendo requisito entonces que todo el terreno esté rodeado de una valla. Además nos indica en qué consiste el nuevo estatuto de la dehesa: asimilación a efectos penales a los terrenos cultivados. No aparece en cambio la fijación de 
una superficie máxima ${ }^{29}$, muy probablemente porque no existiera y los ocilenses gozaran de grandes prerrogativas en lo referente a la transformación de su espacio agrario. De hecho para que la Orden de Santiago pudiera tener sus propias dehesas debió consensuarlo con el concejo: «Et placet nobis, concilio et seniores...» (FRU 194) y, aún a pesar de su condición de señorío, sus dehesas debían someterse a los mismos requisitos que las vecinales.

\section{III.3 Vocabulario}

Por si no fueran suficientes las razones expresadas en páginas anteriores todo lo comentado se puede comprobar de nuevo por otra vía: el vocabulario. Comentábamos brevemente al principio los trabajos de Menéndez Pidal y Lapesa y las particularidades lingüísticas que encontraron en su momento. Estos «occitanismos ajenos al Centro peninsu$l a r^{30}$ », en palabras de Lapesa, no se dan en los artículos idénticos con una única excepción maritatam (FVM 9) por casada, pero que realmente no lo es ya que en FRU 47 aparece maridada. Este cotejo se puede hacer también con aquellos términos que, siguiendo de nuevo a Lapesa, «no siempre es fácil atribuir a determinadas procedencias» ${ }^{31}$. En el fuero de Valfermoso de las Monjas aparecen también otros vocablos como clamauerit (\#\# 7, 8, 9), foras (\# 28) y messe (\#\# 44 y 45) que pudieran ser de origen mozárabe pero también occitano, pero que en vista de sus analogías con $\mathrm{FBr}(\# \#$ 91, 92) y FRU (\#\# 39, 51, 54) no cabe la menor duda en asignarle el primero. En cambio, sí aparecen y con profusión en los artículos finales donde las coincidencias literales con otros fueros han desaparecido ${ }^{32}$ lo que vendría a indicarnos dos tipos de fuentes tratadas con desigual acierto.

\section{CONCLUSIONES}

Los fueros estudiados parecen proceder de un texto que estaría mayoritariamente constituido por artículos de derecho penal y de factura muy sencilla -conducta ilícita y sanción correspondiente-

${ }^{29}$ Como comparación a lo dicho con anterioridad Brihuega (\# 108) señala el requisito del césped, aspecto que no aparece en Alcalá de Henares (\# 272) donde si figura una ampliación de la superficie hasta las tres aranzadas.

${ }^{30}$ LAPESA, R., ob. cit., 1989, pág. 96.

${ }^{31}$ Ib., pág. 95.

32 Todos estos términos figuran en el anexo en negrita para facilitar su seguimiento. 
quedando relegado a un papel secundario el derecho procesal. También se ha podido comprobar en varias ocasiones que en el estudio del derecho medieval estamos condicionados por la personalidad del autor material del texto. En nuestro caso Ebrardo parece ser una persona meticulosa cuando utiliza el texto base, no comete errores de bulto y lo transcribe con bastante fidelidad. No ocurre así cuando utiliza otros materiales en los que se muestra más proclive a los fallos que se manifiestan sobre todo en la utilización de su lenguaje materno y en la colocación de algunos epígrafes en los que se guía más por criterios lingüísticos que legales. Este tratamiento diferenciado estaría fundado en la distinta naturaleza de las fuentes, el texto base bien tendría carácter oficial o bien siendo de origen privado gozaría de un elevado grado de aceptación. El resto de materiales menos homogéneos en su fondo jurídico y de procedencia diversa carecerían de su prestigio y se tratarían de forma menos rigurosa. 
